\title{
SYNTHESIS AND CHARACTERIZATION OF A NOVEL BONE GRAFT MATERIAL CONTAINING BIPHASIC CALCIUM PHOSPHATE AND CHITOSAN FORTIFIED WITH
}

\section{ALOE VERA}

Available online at www.ijdra.com

\section{RESEARCH ARTICLE}

\author{
${ }^{\mathbf{1}}$ Srividya $\mathbf{S} *{ }^{2}$ Sastry T.P., ${ }^{1}$ Jeevitha D, ${ }^{1}$ Samiksha N
}

${ }^{1}$ (Department of Biochemistry, Sathyabama University Dental College and Hospital, Rajiv Gandhi

Salai, Sholinganallur, Chennai-600119, Tamil Nadu, India.)

${ }^{2}$ (Department of Bioproducts, Central Leather Research Institute, Adyar, Chennai - 600020, Tamil

Nadu, India.)

*Corresponding Author's E-mail: srividyabiomed@gmail.com

\section{ABSTRACT}

The bone grafts were prepared using nanohydroxyapatite (nanoHAP) with the extracts of AV and mixed with beta tricalcium phosphate ( $\beta$ TCP) in a ratio of 60:40. The formed BCP was then conjugated with $\mathrm{CH}$ to form the bone graft. The Phytochemicals of AV imparts an anti-inflammatory and wound healing property to the bonegraft in addition to its osteoconductivity.

The bone graft was subjected to various conventional characterization techniques like FTIR, XRD, SEM, UV spectrophotometric analysis, compression and tensile strength to reveal its chemical composition, surface morphology and mechanical strength. The UV spectrophotometric analysis and SEM images revealed the mineral deposition on the bone graft after immersing in SBF, thereby increasing its ossification property. FTIR and XRD revealed the presence of BCP with nano HAP crystals and Chitosan in the graft. Compression and tensile strength of the graft showed that the graft can be used in non-load bearing areas.

In this study, a bone graft was synthesized using a novel technique of introducing the extracts of AV in the graft along with $\mathrm{BCP}$ and $\mathrm{CH}$. The results revealed that the bone graft can be used as an Osteoconductive material for various biomedical applications.

Keywords: Aloe vera; Biphasic calcium phosphate; Chitosan; Nanohydroxyapatite; $\beta$-tricalcium phosphate; Bone graft.

\section{INTRODUCTION}

Calcium phosphate based bioceramics particularly hydroxyapatite (HAP) $\left(\mathrm{Ca}_{10}\left(\mathrm{PO}_{4}\right)_{6}(\mathrm{OH})_{2}\right)$ is widely used as a bone graft material due to its similarity with the inorganic phase of bone. (1) HAP shows the property of biocompatibility, osteoconductivity and non-antigenic response in vivo. $(2,3)$ Currently researchers are showing more interest in mimicking the natural nano composites system for various applications. Though nanoHAP is desirable to prepare bone/dental implants, due to its brittleness and poor mechanical properties biphasic calcium phosphate (BCP) is used in the current scenario. (4) BCP is more advantageous than HAP and $\beta T C P$ due to its controlled resorbability and rapid bone formation around the implant site. The resorbability can be strengthened by adjusting HAP/ $\beta$ TCP ratio. The ratio of 60:40 is found to be ideal for new bone formation and osteoconduction. (5) This ratio shows a high uptake of calcium when compared with other combinations of HAP/ $\beta$ TCP. BCP and biodegradable polymers such as Starch, Collagen, Chitosan $(\mathrm{CH})$, casein, etc are the most suitable candidates for preparing biomaterials for use in bone tissue regeneration and fracture healing.

In this study, we have used Chitosan, a product obtained by the removal of acetyl group from chitin along with BCP. Chitosan is used in various biomedical applications due to its significant antibacterial activity, biodegradability, non toxicity, and 
biocompatibility and beyond this it has positive charge which acts as a binding site for other functional groups. (6,7) Thereby, when chitosan is conjugated with BCP it improves the mechanical strength of the bone graft. The novelty of this paper lies in introducing the phytochemicals of Aloe vera while preparing nanoHAP. Extracts of AV is traditionally used as a medicine for rheumatoid arthritis and it imparts anti-inflammatory and wound healing property to the bone graft. (8-10) In addition to these properties it also provides mineral supplements for the surrounding tissues. This paper focuses on preparing a novel bone graft material using the phytochemicals of Aloe vera, $\mathrm{BCP}$ and $\mathrm{CH}$. The prepared graft was characterized by FTIR, XRD and SEM to confirm their chemical composition and surface morphology. Moreover, mechanical strength of the bone graft was also tested to check its efficacy for use in non-load bearing areas.

\section{MATERIALS AND METHODS}

\section{Preparation of $\beta$-TCP}

An aqueous solution of $\left(\mathrm{NH}_{4}\right)_{2} \mathrm{HPO}_{4}$ (Sigma Aldrich) (325mL) was added to an aqueous solution of $\mathrm{Ca}\left(\mathrm{NO}_{3}\right)_{2} \cdot 4 \mathrm{H}_{2} \mathrm{O}$ (Sigma Aldrich) $(500 \mathrm{~mL})$ under stirring. To this, $5 \mathrm{~mL}$ of ammonia solution was added and stirred for 2 $\mathrm{h}$. The mixture was filtered and dried in the oven at $60^{\circ} \mathrm{c}$ for $24 \mathrm{~h}$. The flakes were then powdered and calcinated in the furnace at $850^{\circ}$ $\mathrm{C}$ for $12 \mathrm{~h}$ followed by cooling to obtain single phase $\beta$-TCP.

\section{Preparation of phytonano HAP}

The whole plant of Aloe vera was collected and washed with distilled water. $2 \mathrm{~g}$ of the whole AV was boiled in $50 \mathrm{~mL}$ of distilled water for $15 \mathrm{~min}$ and cooled to room temperature. $30 \mathrm{~mL}$ of the AV filtrate was added to $350 \mathrm{~mL}$ of $0.4 \mathrm{M}$ alkaline calcium nitrate tetra hydrate solution, mixed thoroughly and incubated for $24 \mathrm{~h}$ at $30^{\circ} \mathrm{C}$. The resulting solution was added to $400 \mathrm{~mL}$ of $0.156 \mathrm{M}$ alkaline diammonium hydrogen phosphate salt solution, stirred and aged for 1 week at an ambient temperature of $30^{\circ} \mathrm{C}$. Then the precipitate was washed several times with deionized water and oven dried at $80^{\circ} \mathrm{C}$.

\section{Preparation of BCP}

BCP was prepared by mixing phytonano HAP and $\beta$-TCP in the ratio of $60: 40$.

\section{Preparation of BCP-AV-CH bone graft}

$0.5 \mathrm{~g}$ of Chitosan $(\mathrm{CH})$ (Sigma Aldrich) was dissolved in $3.0 \mathrm{~mL}$ of distilled water. This $\mathrm{CH}$ solution was added to $5 \mathrm{~g}$ of $\mathrm{BCP}$ and mixed thoroughly to make dough. This dough was extruded through a glass tube $(1 \mathrm{~cm}$ diameter) and dried. These implants were dried initially at room temperature $\left(30^{\circ} \mathrm{C}\right)$ for $2 \mathrm{~h}$ and later at $100^{\circ} \mathrm{C}$ for $5 \mathrm{~h}$, later cooled and stored.

\section{Preparation of Simulated Body Fluid (SBF)}

SBF was prepared by dissolving reagent grade $\mathrm{NaCl}\left(11.994\right.$ g), $\mathrm{NaHCO}_{3}(0.525) \mathrm{g}, \mathrm{KCl}$ (0.336) g, $\mathrm{K}_{2} \mathrm{HPO}_{4} .3 \mathrm{H}_{2} \mathrm{O}(0.342 \mathrm{~g}), \mathrm{MgCl}_{2}$. $6 \mathrm{H}_{2} \mathrm{O}(0.4575 \mathrm{~g}), \mathrm{CaCl}_{2}(0.417 \mathrm{~g})$ and $\mathrm{Na}_{2} \mathrm{SO}_{4}$ $(0.1065 \mathrm{~g})$ in Deionized water. $(11,12)$ The solution was buffered at $\mathrm{pH} 7.4$ with tris (hydroxyl methyl) Amino methane $\left(\mathrm{CH}_{2} \mathrm{OH}\right)_{3}$ $\mathrm{CNH}_{2}$ and $1 \mathrm{M}$ Hydrochloric acid at $36 \cdot 5 \pm 1^{\circ} \mathrm{C}$. (13)

\section{In vitro biomineralization test:}

The biomineralization of the specimen were evaluated by their apatite forming abilities in SBF which was similar to human blood plasma. The prepared cylindrical implant BCPAV-CH was soaked in SBF for 21 days. The immersed specimens were removed from the SBF, then abundantly rinsed using de-ionized water and dried for SEM investigations to show the formation of bone-like apatite layer on their composite surfaces.

\section{Characterization}

UV spectrophotometric analysis was performed for the SBF supernatant at $210 \mathrm{~nm}$ at an interval of 3 days and it was plotted as graph. The IR spectra of the prepared samples were read at wave length range of $4000-400 \mathrm{~cm}^{-1}$ using Nicolet Impact 400 FTIR spectrophotometer using $\mathrm{KBr}$ pellet containing 1-2 mg of the sample. XRD analysis of 
prepared sample was conducted using an analytical X'Pert PRO alpha-1 with a RTMS $\mathrm{X}^{\prime}$ Celerator detector. It used $\mathrm{Ni}$-filtered $\mathrm{Cu}$ $\mathrm{K} \alpha$ radiation over the $2 \theta$ range of $20-80^{\circ}$ at a scan rate of $2.4^{\circ} / \mathrm{min}$ and with a sampling interval of $0.002^{\circ}$ at $40 \mathrm{~mA}$ and $45 \mathrm{kV}$. The surface morphology was analyzed with a Topcon, SM-300 SEM. The copper disc was pasted with carbon tape and the sample was dispersed over the tape. The disc was coated with gold in ionization chamber before microscopic analysis. The implants were made cylindrical in shape with a length to diameter ratio of 2:1 using Instron 4501 model which was designed to minimize the end effect imposed by compressive loading and also with a $0.2 \mathrm{kN}$ load cell or equivalent to check the tensile strength. The compressive strength was calculated from the break load and dimensions of the pellets.

\section{RESULTS AND DISCUSSION}

\section{In vitro bioactivity test}

The prepared bone graft BCP-AV-CH was kept in SBF solution for 21 days at $37^{\circ} \mathrm{C}$. Later the implant was removed from the solution,

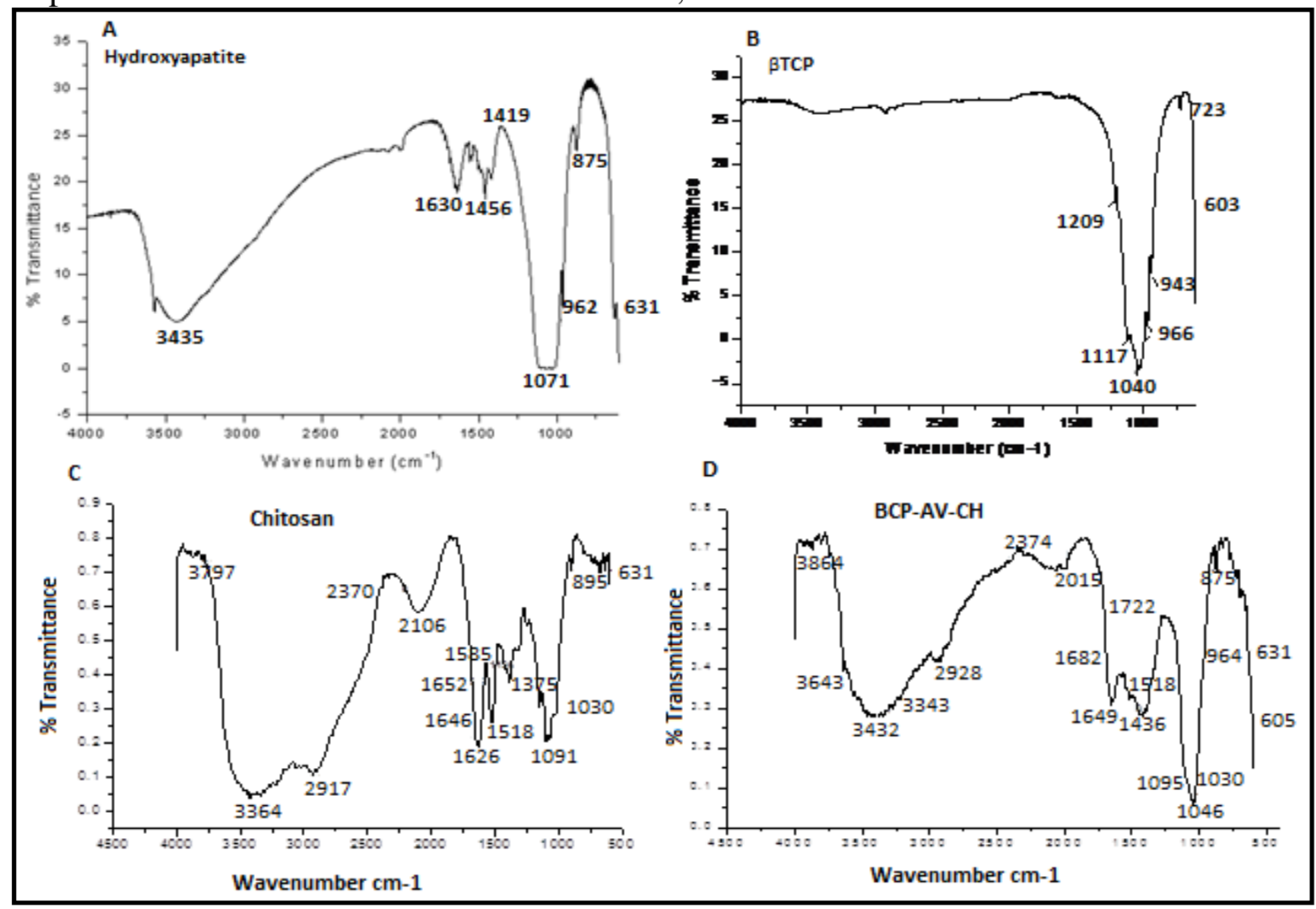

Figure 1: FTIR pattern of (A) phytonano HAP (B) $\beta$-TCP (C) CH (D) BCP-AV-CH graft washed and dried at room temperature. The SBF supernatant was collected and at regular intervals (3days) and subjected to UV analysis.

\section{Fourier Transform Infrared Spectroscopy (FTIR)}

The FTIR spectra of phytonano HAP, $\beta$-TCP, $\mathrm{CH}, \mathrm{BCP}-\mathrm{AV}-\mathrm{CH}$ implant were shown in fig. 1(A) to fig.1 (D) respectively. The band at 605 $\mathrm{cm}^{-1}$ could be assigned to the anti symmetric bending motion of phosphate groups in HA. (14) The $v 1$ phosphate bands representing $\beta$ TCP was seen at $943 \mathrm{~cm}^{-1}$. The $-\mathrm{OH}$ stretching bands of hydroxyl groups were seen around $3500-3700 \mathrm{~cm}^{-1}$. The FTIR spectrum of implant exhibits amide I and II absorption bands at $1649 \mathrm{~cm}^{-1}$ and $1682 \mathrm{~cm}^{-1}$, respectively. The hydroxyl groups of $\mathrm{CH}$ were merged with those of HA and were seen as broad band at 1030- $1095 \mathrm{~cm}^{-1}$. FTIR spectra of $\mathrm{CH} / \mathrm{AV}$ showed the absorption peaks at $3345 \mathrm{~cm}^{-1}$ (O-H), $2928 \mathrm{~cm}^{-1}$ (C-H), $1722 \mathrm{~cm}^{-1}$ $(\mathrm{C}=\mathrm{O}), 1585 \mathrm{~cm}^{-1}$ (hydrogen bonded $\mathrm{N}-\mathrm{H}$ ) and $1030 \mathrm{~cm}^{-1}(\mathrm{C}-\mathrm{O})$. 


\section{UV Spectrophotometric analysis}

Fig. 2(A) shows the UV Spectrophotometric analysis of the implant in which a gradual deposition of calcium and phosphorous attains a stationary phase from 12-21 days. This indicates that the implant once placed in vivo exhibits the diffusion of calcium and phosphorous along with the phytochemicals and causes osteogenesis. (13)

\section{X-ray diffraction (XRD) Analysis}

Fig.2(B) shows the X-ray diffraction (XRD) pattern of $\mathrm{BCP}-\mathrm{AV}-\mathrm{CH}$ and suggest the presence of phytonano HAP and its

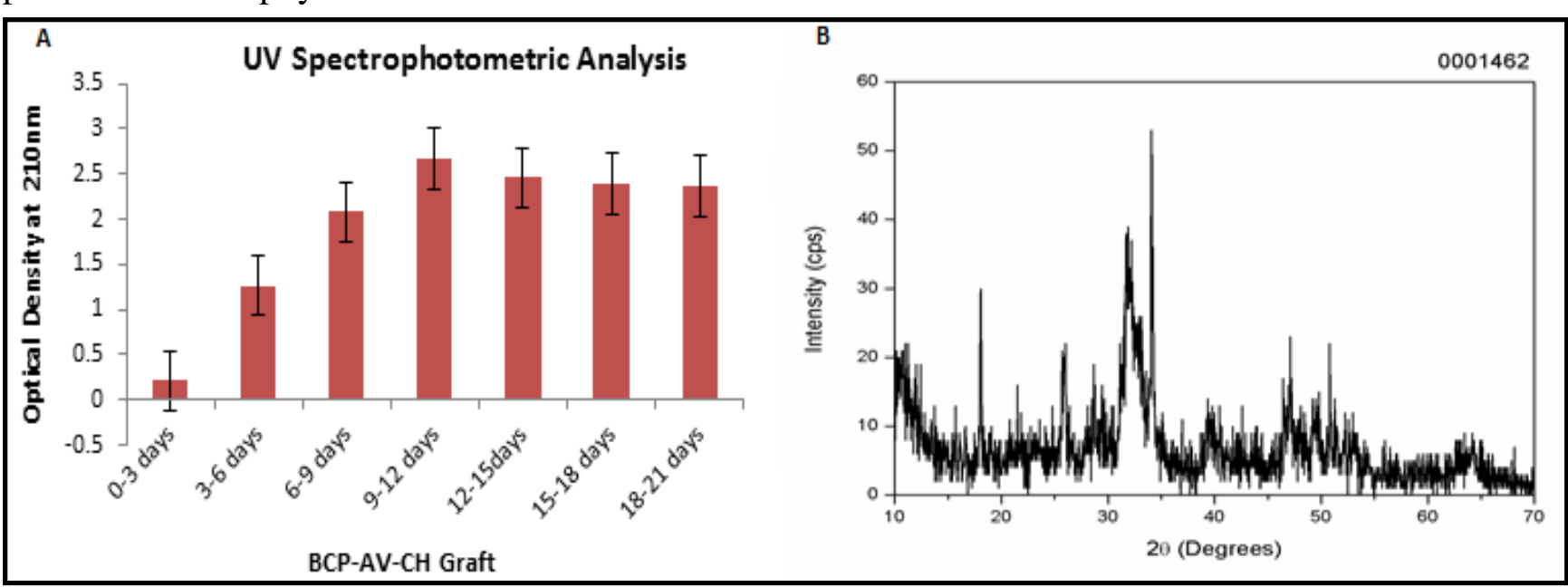

crystallinity decreases with increasing $\mathrm{CH}$ content. The peaks at $19.54^{\circ}, 21.26^{\circ}$ $26.12^{\circ}$, and $28.77^{\circ}$ indicates the reflection from $111,202,002$, and 210 crystal planes, respectively, thereby indicating the presence of phytonano HAP. The peaks at $31.17^{\circ}, 33.119^{\circ}, 48.66^{\circ}$ and $52.7^{\circ}$ indicates the reflection from $222,112,130$ and 315 crystal planes, respectively thereby indicating the presence of $\beta \mathrm{TCP}$ and $\mathrm{CH}$. (15) All the samples show only characteristic peaks of $\beta$ TCP suggesting that its phase did not change into other phases during preparation. This is important for achieving good mechanical and biological properties of produced scaffolds.

Figure 2: (A) UV spectrophotometric analysis of the graft (B) XRD pattern of the implant

\section{Mechanical strength}

Compression tests were performed to characterize the mechanical properties of the prepared scaffolds. The strength of the composite depends upon various factors like composition of the graft, particle size, nature of the additives and percentage moisture present in sample. (13) Fig. 3(A) showed the compression strength of BCP-AV-CH implant before immersing in SBF. The implant depicts the maximum compressive load of $193.40 \mathrm{~N}$ which proves that the material can be used for non-load bearing bone graft material which can be attributed to the presence of $\mathrm{BCP}$ and $\mathrm{CH}$. Tensile properties indicates how the material will react to forces being applied in tension. (16) Fig. 3(B) shows the tensile strength of the implant having $0.49 \mathrm{mPA}$ and has a maximum load been applied $13.82 \mathrm{~N}$ which is suitable to be a non-load bearing bone graft. Here the strength of the material is increased by the presence of $\mathrm{CH}$ which crosslinks with $\mathrm{BCP}$.

\section{SEM analysis}

Fig. 3(C \& D) depicts the SEM images of BCP-AV-CH composites before and after SBF respectively. The SEM images showed that spherical shaped surface indicating the presence of $\mathrm{CH}$ and the $\mathrm{BCP}$ imparts porosity to the material which is due to the presence of $\beta$-TCP in the graft. $\mathrm{CH}$ as a whole creates a porous matrix with $\mathrm{BCP}$ through which phytochemicals along with HA were embedded. The SEM picture of sample after SBF clearly shows the deposition of mineral phase (calcium phosphate) onto the crystals. (17) The aggregation was seen more due to the interconnection of the crystals via calcium 
phosphate deposition. In addition, the polymer network seemed to be porous and ceramic

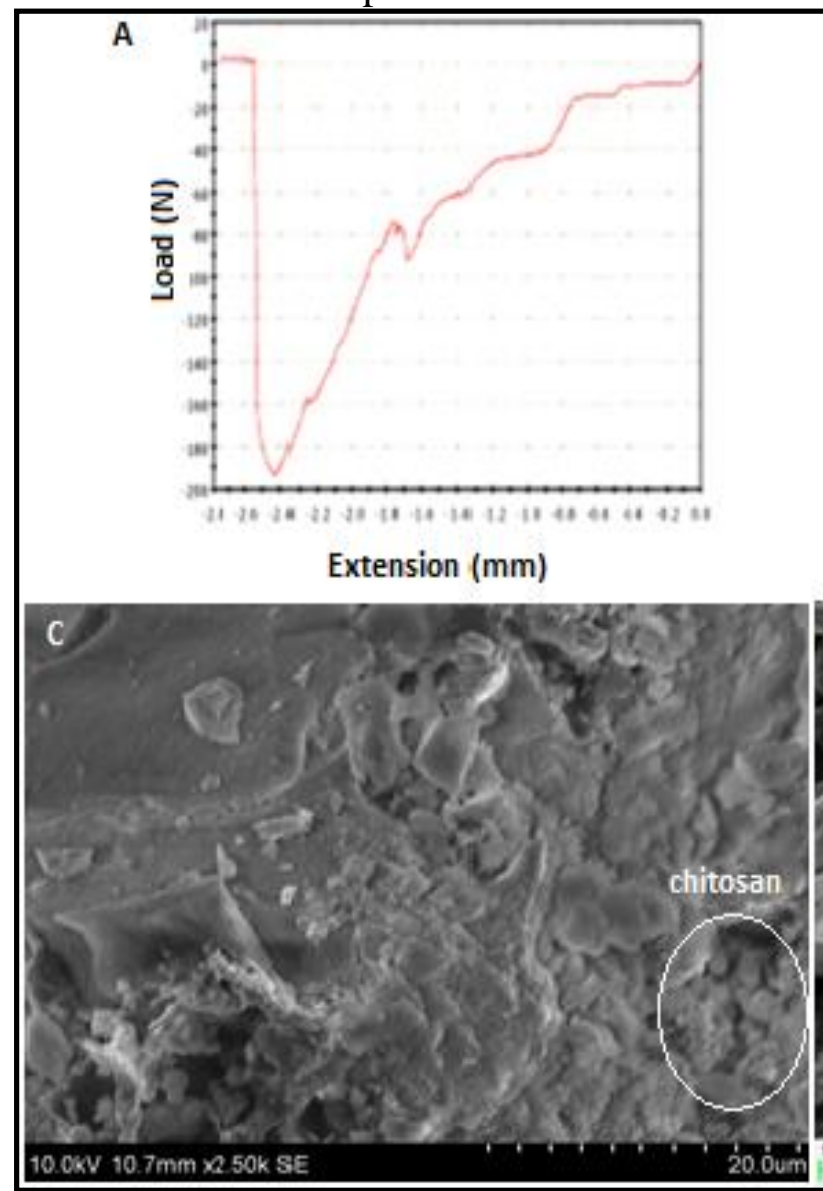

polymer interaction was not disturbed.

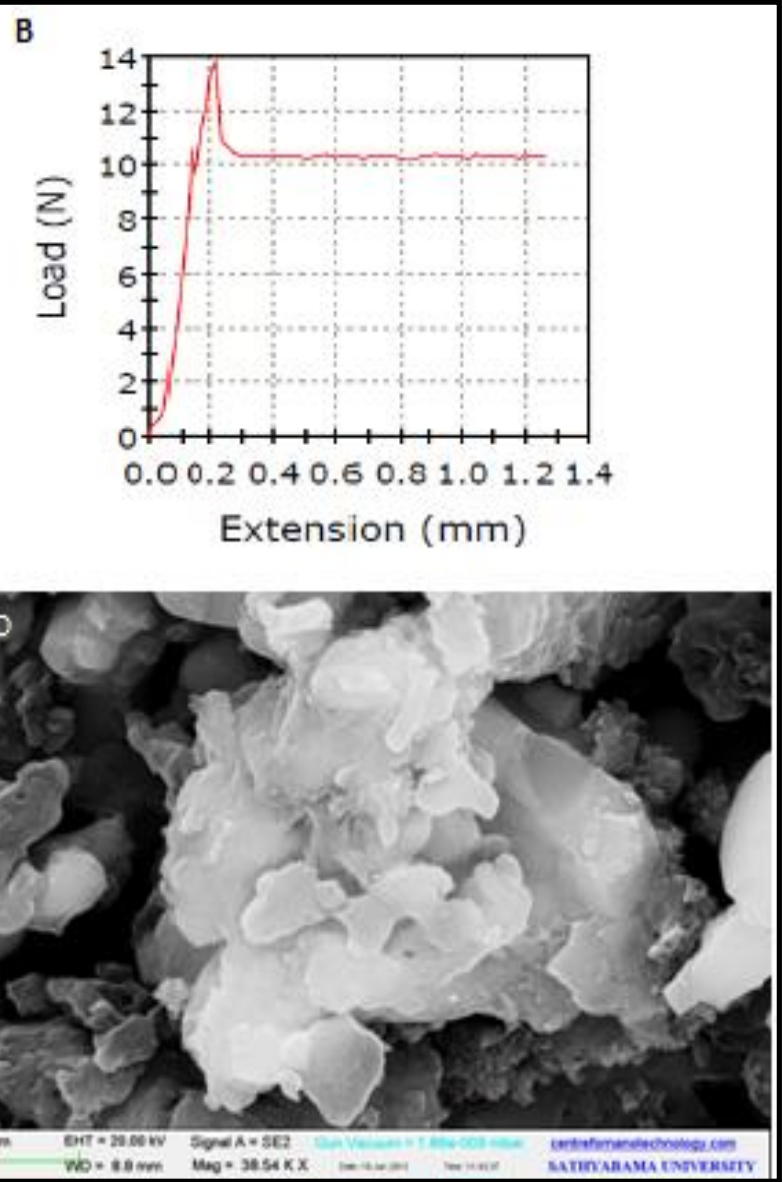

Figure 3: (A) Compression strength of the graft (B) Tensile strength of the graft (C) SEM image of BCP-AV-CH graft before SBF (D) SEM image of BCP-AV-CH graft after immersion in SBF

\section{CONCLUSION}

In this study, a novel bone graft containing Biphasic calcium phosphate was prepared with the phytochemicals of Aloe vera and it was conjugated with chitosan. The bone graft possessed better osteoconductivity and mechanical properties. Hence it can be used for fracture healing and other biomedical applications.

\section{ACKNOWLEDGEMENTS}

We would like to express our sincere thanks to the management Sathyabama University Dental College and Hospitals for providing necessary facility for this research work.

\section{CONFLICT OF INTEREST}

Author declares that there are no conflict of interest.

\section{REFERENCES}

1. TenHuisen KS, Martin RI, Klimkiewiez M, Brown P. Formation and properties of a synthetic bone composite hydroxyapatite-collagen. J Biomed Mater Res. 1995; 29(7): 803-10.

2. Suchanek W, Yoshimura M. Processing and properties of hydroxyapatite - based biomaterials for use as hard tissue replacement implants. J Mater Res. 1998;13(1): 94-117.

3. Fu-Yin H, Shiao-Wen T, Chen-Wen L, Yng-Jiin WJ. An in vivo study of a bone grafting material consisting of hydroxyapatite and reconstituted collagen. Mater Sci Mater Med. 2005;16 (4): 34145.

4. Ding Y, Liu J, Wang H, Shen G, Yu R. A piezoelectric immunosensor for the detection of $\alpha$ fetoprotein using an interface of gold/ hydroxyapatite hybrid nanomaterial. Biomater. 2007; 28 (12): 2147-54.

5. Albrektsson T, Johansson C. Osteoinduction, osteoconduction and osseointegration. Eur Spine J. 2001;10:S96-S101.

6. Shin SY, Park HN, Kim KH, Lee MH, Choi YS, Park YJ, et al. Biological evaluation of chitosan 
nanofiber membrane for guided bone regeneration. J Periodont. 2005;76(10): 1778-84.

7. Qi L,Xu Z, Jiang X, Hu C, Zou X. Preparation and antibacterial activity of chitosan nanoparticles. Carbohydr Res. 2004; 339(16): 2693-700.

8. Reynolds T, Dweck AC. "Aloe vera leaf gel: a review update", J Ethnopharmacol. 1999; 68(1): 337.

9. Shin KH, Woo WS, Lim SS, Shim CS, Chung HS, Kennelly EJ, et al. Elgonica-Dimers A and B, Two Potent Alcohol Metabolism Inhibitory Constituents of Aloe arborescens. J Nat Prod. 1997; 60(11): 1180-82.

10. Umano K, Nakahara K, Shoji A, Shibamoto T. Aroma Chemicals isolated and identified from Leaves of Aloe arborescens Mill. Var. natalensis Berger. J Agric Food Chem. 1999; 47(9): 3702- 5.

11. Tang R, Hass M, Wu W, Gulde S, Nancollas GH. Constant composition dissolution of mixed phases. II: Selective dissolution of calcium phosphates. J Coll Interf Sci. 2003; 260(2): 379-84.

12. Kwon SH, Jun YK, Hong SH, Kim HE. Synthesis and dissolution behavior of $\beta$-TCP and HA $\beta$ BTCP composite powders. J Eur Ceram Soc. 2003; 23(7): $1039-45$.

13. Krithiga G, Antaryamijena P Selvamani Sastry TP. In vitro study on biomineralization of biphasic calcium phosphate biocomposite crosslinked with hydrolysable tannins of Terminalia. Bull Mater Sci. 2011; 34(3): $589-94$.

14. Tas $\mathrm{Cu} \mathrm{K}$, neyt A. Synthesis of biomimetic Cahydroxyapatite powders at $37^{\circ} \mathrm{C}$ in synthetic body fluids. Biomater. 2000; 21(14): 1429-38.

15. Mateus AY, Barrias CC, Ribeiro C, Ferraz MP, Monteiro FJ. Comparative study of nanohydroxyapatite microspheres for medical applications. J Biomed Mater Res A. 2008; 86(2): 483-93.

16. Sarkar KT. Theory and practice of leather manufacture. Chennai: 1965.

17. Ohtsuki C, Kokubo T, Yamamuro T. Mechanism of $\mathrm{HA}$ formation of $\mathrm{CaO}-\mathrm{SiO}_{2}-\mathrm{P}_{2} \mathrm{O}_{5}$ glasses in simulated body fluid. $\mathrm{J}$ Non-Cryst Solids 1992;143:184-93. 